Without observation and classification there can be no science at all.

If, then, we grant that the study of any physical science should predispose the student's mind to this inductive-deductive method of truth-seeking, how can we teachers of astronomy fail to recognize that when we are eliminating entirely, or even subordinating, observational and experimental work with our classes and depending entirely upon the text-book that we are doing just about as good as no teaching at all?

The series of experimental exercises which the writer promised in the March number, and which are intended to bring within easy access of all readers of ScHOOL SCIENCE, who are desirous of ptitting high school astronomy on a modern basis, the means of doing so, will be begun in the first issue in the fall.

\title{
INFLUENCE OF EXPECTATION IN QUANTITATIVE WORK.
}

By N. A. Harvey.

Department of Natural Science, Chicago Normal School.

In the March number of School ScIENCE is an article upon "Quantitative Experiments in Chemistry for High Schools," which contains an excellent estimate of the advantages to be gained from quantitative work in chemistry. In illustrating the possibilities of quantitative wcrk, the writer gives some examples of accurate results obtained by large classes. The examples are certainly very remarkable, and the difference between the extieme results reported is very small. Certainly such work must be productive of the greatest benefit to students.

But one circumstance was omitted upon which will depend, in a very great measure, our estimate of the benefit the student derives from such work. Did the students know before completing their work how much they ought to get, or just about what the answer should be? Any one who has studied the influence of expectation upon judgment knows how much it modifies a conclusion. If, in a quantitative determination, a student knows what result he ought to get, he will get that result almost in spite of himself. It is not necessarily something dishonest, but it is 
unavoidable. This is true in quantitative chemistry, it is true in qualitative chemistry, it is true in physics, it is true in biology.

The present writer used for some years a very excellent laboratory manual of zoölogy, containing laboratory directions for the study of a perch. It happened to be more convenient to furnish sunfish for class use, which are very similar fish. The laboratory directions indicated that teeth would be found on the palatine bones. Ordinarily about two-thirds of the class would find teeth on those bones, when in fact the sunfish, which was the one they were studying, has no teeth in that situation.

In quantitative work in chemistry, the pupil is likely to obtain a knowledge of the correct answer to a particular problem. $\mathrm{He}$ may get it from the teacher, from a text-book, from reference books, or from the note-books of a previous class. If pupils do have such information it takes away a large part, I should say the larger part, of the value accredited to accurate results.

Equally vicious results are met with in biological subjects. When I go into a laboratory and see note-books containing drawings of the objects that the pupils are studying that look exceedingly like pictures in books with which I am familiar, I at once enter an indictment containing the charge of false pretenses. When I see hung around the walls finely executed charts labeled with a pupil's name, and professedly drawn by the pupil from the object, but which are exact reproductions of figures in standard books, I feel that I am in an art room instead of a laboratory, or that there is need of conversion on the part of some one. Of course the pupil can find all the mouthparts of a crawfish if he knows what they are beforehand, what they look like, and the order in which they come, and especially if he works with a picture or mounted specimen before him. That is not the question. Can he determine for himself the number, kind and arrangement of the mouthparts from the crawfish alone, without other assistance? That will constitute a measure of his power, and a promise of future success.

It is particularly the province of scientific subjects to make the student independent, self-reliant, and capable of seeing things as they are, and not merely as he thinks they ought to be, or as some one else says that they should be. If science fails to do this 
it fails to accomplish a large part of the purpose for which it is introduced into the curriculum.

It is the old story of the pony in Latin and the key in arithmetic and algebra. Teachers of Latin and mathematics have got beyond the stage of the pony and the key. I do not say that teachers of science have not, but some things that $\mathrm{I}$ have seen leads me to suspect that this touches upon the weakest spot in the science teaching of even our best high schools.

The only method I know to avoid the obtaining of information in what I consider an illegitimate way, is to start right with a class and cultivate the proper spirit toward the work. I know that the proper spirit can be cultivated so that pupils will not seek information about their experiment except from the experiment itself, and that the effect upon the character and intellect of the pupil is vastly stuperior to that which results from the usual method.

\section{THE MODERN PRESENTATION OF BOTANY.}

By A. M. Ferguson.

Instructor in Botany. University of T'exas.

Botanists are interested in the advancement of science, whether it be by encouraging investigations in new fields or by the diffusion of knowledge already accumulated. The latter may be secured by popular lectures, magazine articles, etc., but the most thorough, useful and substantial advancement is begun in our public schools. The school science teaching, then, merits our earnest attention for this reason. In advocating higher standards of science it may be said for the non-scientific that it is not for science's sake, but for the school's sake. No science is an end in itself, and the advancement of science is not the question of greatest moment. "Instruction in any subject should develop a capacity for thought and conduct and no scientist wishes to shirk his share of responsibility in training for good behavior and good citizenship. If he has not this faith his right to spend his time in the advancement of science becomes a matter of question. * * * From the standpoint of its effect upon character and 